\title{
A Morpho-Syntactic Study of Contemporary Science Fiction Short Stories
}

\author{
Nadya Khairy Muhamed Said ${ }^{1}$ \\ ${ }^{1}$ Department of English, College of Education Ibn-Rushd for Human Sciences, University of Baghdad, Iraq \\ Correspondence: Nadya Khairy Muhamed Said, Department of English, College of Education Ibn-Rushd for \\ Human Sciences, University of Baghdad, Iraq. E-mail: nadya_khiere@yahoo.com
}

\author{
Received: December 13, 2018 Accepted: February 8, 2019 Online Published: April 6, 2019 \\ doi:10.5539/ijel.v9n3p117 URL: https://doi.org/10.5539/ijel.v9n3p117
}

\begin{abstract}
The aim of the present study is to research two morphological processes: acronym and compounding (phrasal compounds/circumlocution) and one syntactic category which are 'existential sentences' in science fiction short stories. The present paper identifies different types and rates of existential sentences. In this respect, 'bare existential and locative' read the high percentages and may be contrasted with other classifications of English existential sentences which have a verb other than 'be' and a definite expression. 'Phrasal compounds' vary in rates as they constitute notable percentage for those that involve 'lexical means and lexical relations' followed by 'prepositional compounds', 'conjunctional compounds', and those involve 'a noun, pronoun, and an adjective'. Furthermore, 'phrasal compounds' containing a verb' having the value of zero. Analysis of data has acknowledged that 'atomic' acronym constitutes the high percentage than 'molecular' and this explains the abundance of the unpronounceable acronym in science fiction. Generally, existential sentences, existential sentences may give the entire clause a fresh status.
\end{abstract}

Keywords: atomic acronym, existential sentences, molecular acronym, phrasal compounds/circumlocution, science fiction

\section{Introduction}

The present study is within the framework of science fiction which is one of the most popular and commercially successful genres of the 20th century. The boundaries among the technological, the personal and the virtual have been redrawn in the computer age, and this self-conscious concern with the status of reality and fiction continuous into 1990s.

An extension of this, which also suggests a form of communication about technology and science/fiction, is the 'acronym'. In this respect, science fiction will be examined morphologically and syntactically through a number of contemporary notable science fiction short stories. A particularly fruitful form of word-formation process has been also investigated namely, 'compounding' of 'phrasal circumlocution' in order to prove its survival in science fiction short stories.

Interest has been concentrated on the structure and the classification of 'there-family' (Ross 1977), i.e., 'Existential Sentences' which is now the subject of a very considerable literature.

Further and more focus study with bigger data is needed to confirm and give support to the findings and conclusions. Though, eight contemporary science fiction short stories have been tackled to do the requirement. These short stories are: Avatars of Mars by Jake Bartolone (2003), The Thursday Night League by James Hartley (2008), Minds Game by Dylan Fox (2009), Dog Star by Jeffrey Carver (2009), Galactic Stress by David Levine (2009), The Freshmen Hook Up by Wil McCarthy (2009), Life on Mars by Deborah Kean (2013), Beauty and the Bot by Athul Krishna A. (2015).

Hopefully, the present paper is expected to be significant for teachers of English linguistics, researchers, and all those who are wholly or partially interested in the study of 'science fiction'.

To the best knowledge of the researcher, no paper has addressed this topic under contemporary science fiction short stories. It is time to regard it as an outstanding aspect in science fiction literature.

To this stage, this paper tries to answer the followings questions: 
1) Does 'atomic' or 'molecular' acronym read the most frequent type in science fiction short stories?

2) In accordance to their internal structure, what are the common classifications of 'phrasal compounds' which are prominent in the data under analysis?

3) What are the emerging forms/groups of 'Existential sentences' in science fiction short stories?

\section{Science Fiction/Science Fiction Short Stories: Literature Review}

The term science fiction tries to explore various predictions by fiction. It tries to explore predictions by depicting the influences of cutting-edge technology on the future of human and communities.

Historically, science fiction has always studied the connection between machine/technology and magic and human. It offers challenging narratives as a genre which should be used as pedagogical tools to critically change what it considered as curriculum and learning to be, as well as when it settles (Thomas, 2013, p. 118). There is no need to say that science fiction is regarded as a combination of literature and science, science because it depicts science and technological advances, and literature because of its fictional events and characters. These (events and characters) are created by the authors. Needless to mention that science fiction often portrays the fictional scientific advances that became involved with the future of humans. It (science fiction) comprises different futuristic elements of human, society and culture as a literary genre of scientific ideas and philosophy (Mirenayat et al., 2017, pp. 4-5).

Science fiction has been one of the most influential literary genres since the 19th century through endless stories that reflect different reflexes in human life and technology. Writers of science fiction take us into imaginary worlds. They show both terrifying results of technological applications and promising into the life of future human (Ibid.) Similar to comics/graphic novels, science fiction and speculative fiction are genres that "move readers to imagine alternative ways of being alive"-notably in that they have thrived in a wide range of media from traditional text-only works to TV and movies to comics/graphic novels. Like comics and graphic novels (Thomas, 2010, p. 24).

Science fiction is linked strongly to the market: "Science fiction as a self-conscious publishing category is generally considered to have begun in 1926, when editor Hugo Gernsback published the first issue of 'Amazing Stories', the first magazine devoted exclusively to science fiction" (Booker \& Thomas, 2009, p. 7).

Science Fiction short stories are prominent element in the development of the genre. They are regarded as an important connection between medium and genre as well as a powerful element in the double-edged sword of popularity for the genre. Seemly, Science fiction basically created a keystone between the critics and the genre. Booker and Thomas (Ibid.) explain that 'Amazing Stories 'established a key arena for the next editor, John W. Campbell, and writers-Isaac Asimov, Lester Del Ray, Robert Heinlein, Theodore Sturgeon, A. E. Von Vogt.

Significant science fiction texts have cornered on technological ranks and advancements starting from the beginnings of the 20th century along. Such as 'Brave New World' (1932) by Aldous Huxley (British author 1899-1963). 'I', 'Robot' (1950) by Issac Asimov (American writer, 1920-1992) and other science fiction novels (Best \& Kellner, 2001, p. 103).

As an interdisciplinary literary genre, science fiction builds a special unique language by which writers predict its negative and positive effects. Further, science fiction creates this uncommon language by which writers by foreseeing human future life (Bostrom, 2005, pp. 87-89).

Reider (2012, pp. 1-2) believes that:

The term science fiction became widely used in the pulps in the 1930s, and it is strongly associated with the dominant form taken by it in the 1940s and 1950s pulp magazines, a period that continues to be called science fiction's Golden Age even though the honorific connotations of that period term have long ago faded away". Science fiction was the term that almost would appear on the cover of a paperback to represent its genre to potential reader in the 1950s, when the market for this kind of fiction began to move from the pulp magazines to paperbacks.

Science fiction became interested in matters of realization, subjectivity and the influence of technology on the personal life, in the 1960s, beginning in Britain but relating American writers and spreading to the US. It is worth noting that this 'New Wave' was resembled by a new self-consciousness in style. Further, this 'New Wave' was matched with experiments in form and content emerging in the science fiction magazines. The 1970s identified the science fiction is being used toward new political ends (it was approved by the women's movement) to state the wish and desire for a more equal society, whether by inverting reality, and extrapolating oppression from aspects of our own world (Stock well, 2000, p. 15) 


\section{English Word Formation Process}

\subsection{Acronym}

'Acronymization' is defined by Booij (2007) as "a morphological process in which a combination of initial letters of a word sequence is pronounced as a word". A good example can be found in English and French such as NATO (North Atlantic Organization) and a French example OTAN (Organization du Traité de l'Atlantique Nord).

Bauer (1983) in Danks (2003, p. 98) add that acronym is "a word coined by taking the initial letters of the words in a title or a phrase and using them as a new word". For example, 'SALT' to indicate 'Strategic Arms Limitation Talks'. Acronyms "may include other than initial letters to make them more word-like (Quirk et al., 1985, pp. 1581-1582; Danks, 2003, p. 99). A good example is 'radar' to refer to 'Radio Detecting and Ranging'. So far and accompanying may omit also some 'non-lexical' words in the source phrase. For example, 'laser' 'Light Amplification by the Stimulated Emission of Radiation'.

Plag (2002, p. 163) says that when the acronyms are pronounced as words, they may include initial and non-initial letters, or a mixture of initial and non-initial letters. He further adds that they may also be pronounced as a mixture of two, i.e., 'a combination'. For example, 'IUPAC' /airpark/.

Stockwell (2000, p. 119) adds that taking the initial letters of words can be 'atomic' in that every individual letter is pronounced. 'Molecular' in which the acronym is pronounced continuously as if it was a word. As for the first one (atomic), 'AI' is a clear example which refers to (artifial intelligence), whereas 'molecular' examples include Lessing's 'sowf', and 'HAL' in 'Hardware Abstraction Layer'.

Acronyms and abbreviations are "product of irregular word formation" (Lijung, 2003, p. 153). He (Ibid) claims that there are two main types of word formation: 'irregular and regular word formation'. 'Regular' is concerned with the process of adding inflections to words in order to construct words that belong to another grammatical category. For example, adding a suffix to a noun in order to make an adverb or adjective. The second type 'irregula' $r$ ' which makes new words to enhance the vocabulary.

\subsection{Compounding}

Bauer (2001, p. 695) points out that "Compound is a lexical unit made up of two or more elements, each of which can function as a lexeme, independent of the other(s) in other contexts, and which shows some phonological and/or grammatical isolation from normal syntactic usage".

Plag (2002, pp. 170-208) states that "compound or compounding or compositions may consist of more than two more members word”. For example, 'University Teaching Award Committee Member'. In addition, Bauer (Ibid.) claims that compounding includes binary structures that may repeat to shape a new compound. This is named 'recursively'. 'Recursively' refers to one compound or more can be added to an occurring/standing compound. Ralli (2013, p. 10) says that "compounds consist of more than one lexeme which can be realized as words or stems based on the language under investigation."

Bauer (Ibid.) argues also, that "actually a compound is not always and only a combination of words like what is mentioned above, but also including the use of plural noun as the element of the compound". For example, 'Systems analyst'.

Another example of a combination of roots is 'biochemistry': 'bio' is a bound morpheme which behaves like word not affix. So, 'biochemistry' is a combination of bound and free morphemes. If the words are linked to make another single word, these are often called 'lexical blends'. For example, 'holodeck' and 'orgasmatron'. Also, words can be shaped as noun and verb compound like, 'wrap-drive', or as adjective and verb 'doublethink'. It is worth mentioning that most common familiar forms of adjective are the collection of noun and noun as 'ion-gun', 'rim-world', etc. (Stockwell, 2000, p. 118).

The term 'phrasal circumlocution' is another type of compound which is a formation of lexical item. Lessing's (1981a) 'sense-of-we-feeling' or (its acronym 'sowf') is a complex noun phrase used to describe a new way of thinking (Ibid, pp. 118-119). Other examples of phrases what maintain a sense of their origins and newness is: 'cultural engineering', 'hollow earth' and 'alternate world'.

Bauer (1983, p. 206) suggests 'phrase compounds' as "constructions where an entire phrase seems to be involved in the formation of a new word". He suggests a classification into three categories/subsequent subcategories as follows:

A- 'Endocentric phrase compounds': 'lady in waiting', 'a what-do-you-think-movement'. 
B- Dvandva constructions: they look the least like compounds and the most like syntactic phrases as 'milk-and-water'.

C- Exocentric phrase compounds: a variable group that comprises for example: plant and standing for names: 'forget-me-not' (plant name), has 'been' (to denote people).

Similarly, Nosek (1985, p. 159) uses the term quotational compounds and defines them as "multiword groups", "mostly hyphenated", "consisting of three or more words or morphemes". He (ibid) excludes two-word phrasal compounds.

Here is the classification of phrasal compounds in accordance to their internal structure (Ibid, pp. 161-162):

A- Phrasal compounds which include nouns, pronouns or adjective such as 'a fish-and-chips shop' and 'all-or-nothing decision'.

B- Phrasal compounds with a verb:

1) A finite verb in the indicative such as 'a do-it-yourself job' and in the indicative as 'a boys-will-be-boys excuse'.

2) Gerund, participle and infinitive as 'bride-to-be, teacher-turned-President'.

3) Verb with an unclear status such as 'happy-go-lucky man'.

C- Conjunctional phrasal compounds may also be subdivided into three groups according to the conjunction as the following: 'and, or, than', 'larger than life', 'touch and go', 'all-or-nothing matter'.

D- Prepositional phrasal compounds are subdivided in accordance to the preposition: such as: 'to, up, of, in, within, etc.: 'flight-by-night', 'off-the-shoulder blouse', 'on-the-spot report'.

E- A classification based on lexical means and lexical relationships as the following classifications (Ibid, p. 162):

1) Symmetrical phrasal compounds: one of the components is repeated such as 'day-to-day'.

2) A symmetrical phrasal compounds which do not contain a repeated element although the elements are semantically related such as 'hand-in-glove'.

3) A symmetrical phrasal compounds which do not have a noun as their first but as the third component as 'off-her-shoulder blouse'.

4) Phrasal compounds which are together symmetrical and a symmetrical contain a semantic contrast to repeat one of the components: 'take-it-or-leave-it'.

\section{Existential Sentences}

The term 'existential sentence' goes back somewhat as far as Jespersen (1942, p. 155) and is used "to describe many languages in order to refer to a designated construction. So, it is difficult to distinguish what these constructions have in common cross linguistically." In many languages, existential sentences have a special syntactic shape, different from regular subject-predicate sentences, as illustrated by English sentences:

1) There are two holes in my left pocket.

2) Two holes are in my left pocket.

"Existential constructions are constructions with non-canonical morph syntax which express a proposition about the existence or the presence of someone or something in a context "(Francez, 2007; Mc Nally, 2011. p. 1830).

On the other hand, Bolinger (1977, p. 94) claims that "existential 'there-sentences' have often been characterized as serving a 'preventative' discourse function i.e., drawing attention to an element that comes into the view or to the attention of the addressee". He (Ibid.) adds that "the construction "presents something to our minds includes a piece of knowledge which is brought into consciousness"'. This is accounted to introduce explicitly an item into the world of discourse.

Downing and Locke (1992) say that "there typically has a function in which the indefinite subject is moved to another position for the purpose of the 'end-focus' and the 'end-weight' principle".

Furthermore, Collins and Hollo (2000) point out that "existential sentences permit few verbs to follow the preventative 'there'”. Examples are 'remain', 'appear', 'follow', 'seem', and 'emerge'. 
Quirk et al. (1980, p. 1402) point out that English employs the existential 'there' in order to avoid beginning an utterance with the theme which carry new information. In this respect, 'a ghost is the cave', the speaker says 'there is a ghost in the cave'. This tells that the sentence with an indefinite theme is felt to be clumsy/stiff.

Existential sentences in English may be grouped under four headings (Ibid. 1, pp. 1402-1414):

A- Locative existential: it claims the existence of an entity in a certain location. It has the structure (there, be, prediction). It can directly be related to the basic pattern of English sentences as in this example:

3) In the next room, a professor is giving a workshop-In the next room, there is a professor giving a workshop.

B- Bare existential: that affirms the absolute existence of a person/thing that have the construction: (there, be, nominal expression). See the following example:

4) There is no justice.

5) There are many people who would like to do it.

6) There is no way to stop.

Sentences $(5,6)$ show the construction which includes the patterns where indefinite expression is modified either by 'to infinitive' or 'relative clause pattern'.

C- Existential with other verbs than 'be' such as verbs that point out appearance or coming into existence, as in the following (Breivik, 1981).

7) There appeared some clouds in the horizon.

D- Existential with a definite expression (there, be, definite expression). This definite existential are termed as 'list sentences'. "Existential 'there-construction' with a definite notional subject tend to occur when a series of elements is introduced often marked explicitly by a conjunction or linking adverb(first) or additive adverbials (too)" (Biber et al., 1999, p. 947). The following examples illustrate this type:

8) First, there is the lecture with a meeting.

9) How could we get there?-Well, there's the trolley.

\section{Data Analysis}

Morphologically, the present paper manipulated two morphological processes, namely, 'acronym' and 'compounding' for the analysis of science fiction short stories.

\subsection{The Classification of the Acronym}

As for acronym (classification of Stock well, 2000), the paper reveals 26 acronyms from the whole data which are classified according to 'Atomic' which reads 21 out of 26 . This constitutes $81 \%$, whereas, 'Molecular' reads 5 only from the total number of acronyms which constitutes $19 \%$. See Tables 1 and 2 below:

Table 1. Atomic acronym

\begin{tabular}{ll}
\hline Atomic Acronym & Identification \\
\hline U.N. & United Nations \\
ID's. & Identity \\
YMCA & Young Men's Association \\
SOBs & Son of a Beast \\
WSA & Water Supply Act \\
EFST & Environmental Field Sampling Study \\
HND & Hemolytic Disease of the New Born \\
IQ & Intelligence Quotient \\
AI & Answer Indicator \\
IP & Artificial Intelligence Protocol \\
TV & Television \\
GPS & Global Positioning System \\
ESA & Emergency Service Access \\
LEDs & Light Emitting Diode \\
Ph.D & Philosophiae Doctor \\
L2 & Level 2 \\
HVF & High Voltage Fuse \\
Atomic Acronym & Identification \\
U.N. & United Nations \\
\hline
\end{tabular}


Table 2. Molecular acronym

\begin{tabular}{ll}
\hline Molecular Acronym & Identification \\
\hline NASA & National Aeronautic and Space Administration \\
OK & Okay \\
EMAIL & Electronic Mail \\
EUROs & European Monetary Unit \\
Bot & Robot \\
\hline
\end{tabular}

These two tables exemplify the two types of acronym and their identifications according to the texts they represent i.e., science fiction short stories.

In the following table, 'atomic' and 'molecular' acronyms are stated with their frequencies and percentages:

Table 3. The frequencies and the percentages of 'Atomic' and 'Molecular' acronym

\begin{tabular}{lll}
\hline Type of Acronym & Frequency & Percentage \\
\hline Atomic & 21 & $81 \%$ \\
Molecular & 5 & $19 \%$ \\
Total & 26 & $100 \%$ \\
\hline
\end{tabular}

\subsection{The Classification of Phrasal Compounds/Circumlocation}

According to the classification of (Nosek, 1985), 'Phrasal Compounds/Circumlocution' is formulated in this paper that comprises the total number 16. As for that classification which involves 'noun, pronoun, and adjective', its representation is 2 only from the total 16 which reads $13 \%$. 'Conjunctional phrasal compounds' involves 3 from the total 16 and it reads $19 \%$. 'Prepositional compounds' constitutes 4 and reads $25 \%$. The classification based on lexical means and lexical relationships constitutes 7 from the total number 16 and it reads $44 \%$ which is the highest percentage comparing to the rest groups. In order to set the stage, the following table figures out the classification of phrasal compounds:

Table 4. Classification of phrasal circumlocution/compounds in accordance to their internal structure

\begin{tabular}{|c|c|c|c|}
\hline Classification & Phrasal Compounds & Frequency & Percentage \\
\hline Involve noun, pronoun, adjective & $\begin{array}{l}\text { The-third-most-powerful-scientific data. } \\
\text { Much-too-bright flare }\end{array}$ & 2 & $13 \%$ \\
\hline Conjunctional Phrasal Compounds & $\begin{array}{l}\text { Three-hundred-and-seventy-nine a month } \\
\text { Four-hundred-and-sixteen } \\
\text { Black-and-white }\end{array}$ & 3 & $19 \%$ \\
\hline Prepositional phrasal compounds & $\begin{array}{l}\text { Picture-over-IP } \\
\text { Quarter-past-eighteen } \\
\text { Evening-going-on-night } \\
\text { Little-to-no }\end{array}$ & 4 & $25 \%$ \\
\hline Lexical means and lexical relationships & $\begin{array}{l}\text { Five-year-old } \\
\text { Half-an-hour } \\
\text { Half-a-dozen } \\
\text { One-of-a-kind } \\
\text { Six-foot-cubed coffin } \\
\text { Thirteen-year-old } \\
\text { Multi-billion-dollar }\end{array}$ & 7 & $44 \%$ \\
\hline Containing a Verb & $\begin{array}{l}\text { None } \\
\text { Total }\end{array}$ & $\begin{array}{l}\text { Nil } \\
16\end{array}$ & $\begin{array}{l}\mathrm{Nil} \\
100 \% \\
\end{array}$ \\
\hline
\end{tabular}

\subsection{The Classification of Existential-There}

The syntactic category analyzed in this paper is 'existential-there' and they are examined in terms of (Quirk et al., 1980). The total number of 'existential-there' is 66. 'Bare Existential' reads 36 from the total number 66 and this constitutes 55\%. 'Locative Existential' reads 25 and this constitutes 38\%. 'Existential with a definite expression' and 'Existential with a verb other than be' constitute least percentages as $6 \%$ for those of a definite expression and 3\% for those which contain a verb other than 'be'. The properties of the four types of existential sentences are summed up in the following Table 5. 
Table 5. Headings of existential sentences

\begin{tabular}{lll}
\hline Headings & Frequency & Percentage \\
\hline Bare Existential & 35 & $53 \%$ \\
Locative Existential & 25 & $38 \%$ \\
Existential with a Definite Expression & 4 & $6 \%$ \\
Existential with a Verb other than 'Be' & 2 & $3 \%$ \\
Total & 66 & $100 \%$ \\
\hline
\end{tabular}

Below are the examples of bare, locative, existential with a definite expression and existential with a verb other than 'be' that emerged in contemporary science fiction short stories:

Table 6. Data analysis of existential sentences

\begin{tabular}{|c|c|c|c|}
\hline Bare Existential & Locative Existential & Existential with a & Existential with a \\
\hline 1) There's no way to identify them even if .... & 1) “There were no work postings & Definite Expression & Verb other than 'Be' \\
\hline 2) There's no evidence that ...even if there were & scheduled for that area". & 1) ..., there's a bay. & 1) There comes a \\
\hline more ... & 2) "There's a critic on every & 2) Well, yeah. That's & point in the puddle's \\
\hline 3) There are three hundred colonists. & ship”. & because there's a & expansion when a \\
\hline 4) There are as many differences among the & 3) ..., and there was suddenly a & force-". & large ... \\
\hline colonists & much-too-bright flare of rocket & 3) "There's one thing & 2) There were \\
\hline 5) There was no answer, and he knew ... & exhaust in his peripheral & we can try, said & supposed to be \\
\hline 6) So, there was no way they could fly back under & vision ... & Keith" & safeguards. but the \\
\hline their own power. & 4) "There must be something in & 4) "here's time" he & HVF was... \\
\hline 7) There used to be redundancy? & here we could signal ..." & told the others & \\
\hline 8) There's something that's always bothered me. & 5) “There's plenty of dust and & & \\
\hline 9) There's special kind of supernova that & loose stuff here". & & \\
\hline astronomers know are all pretty ... & 6) There was a lot of space to & & \\
\hline 10) ...thing is, there's this special kind of & cross between here and the base & & \\
\hline supernova that astronomers know are all... & station. & & \\
\hline 11) ...there are creatures so vastly much larger & 7) ...for there are large numbers & & \\
\hline than the Bitomites that mere philosophy... & of Freshmen hanging around the & & \\
\hline 12) ...there are peculiar things that can happen in a & periphery... & & \\
\hline rain puddle when it gets... & 8) ..., there's an undeniable & & \\
\hline 13)There's just few on the black list, people who & menace behind them. & & \\
\hline have, well, over-cooperated with ... & 9) There were two guards on duty & & \\
\hline 14) Funny thing, I thought there was something & at the door. & & \\
\hline familiar about the locations and ... & 10) There was a new kind in my & & \\
\hline 15) If there was anything to see, we should be ... & department, Joe Collins. & & \\
\hline 16) He thought there was more to it, ... & 11) ...there's nothing except & & \\
\hline 17) And there might well be! & business in them. & & \\
\hline $\begin{array}{l}\text { 18) She noted that there were stairs, weathered and } \\
\text { rounded (how)? }\end{array}$ & $\begin{array}{l}\text { 12) There were some directions I } \\
\text { haven't been able to safely crack }\end{array}$ & & \\
\hline 19) ....and there was no way to tell what color his & from my ID at work. & & \\
\hline eyes had been... & 13) There was something there & & \\
\hline 20) There was a medical bed. & worth investigating yes, and ... & & \\
\hline $\begin{array}{l}\text { 21) There was no need for it anymore - the narrow } \\
\text { vision it ... }\end{array}$ & $\begin{array}{l}\text { 14) There was a door in the hill, } \\
\text { let into the side ... }\end{array}$ & & \\
\hline 22) She had been warned that there could be & 15) There should not be any & & \\
\hline perceptual side effects, and ... & changes in the irises at all. & & \\
\hline 23) There might be more universe beyond that limit & 16) ....but there was no way for & & \\
\hline —in fact, there most ... & anyone on Earth to know & & \\
\hline 24) There's a double-bed, a wardrobe which is & anything about it. & & \\
\hline older than me, ... & 17) There was just some kind of & & \\
\hline 25) There's a window which opens so you can & glitch in the system. & & \\
\hline breathe in the views of the cobbled road... & 18) There was an awful lot of & & \\
\hline 26) There's thick curtain so you can block it all out. & mostly empty space in the solar & & \\
\hline 27) "There was ...your brother." she glances up at & system. & & \\
\hline me, ... & 19) There were tears in her eyes. & & \\
\hline 28) ...there's security guards and bullet-proof glass & 20) There's a lifetime of smog & & \\
\hline that you need a swipe card to get... & and sweat and grease and dirt in & & \\
\hline 29) I get back and there's two missed calls for me. & my lungs and it... & & \\
\hline 30) ..., and there's nothing. & 21) There's a waiting area with a & & \\
\hline 31)..., and there's people jogging and walking & $\begin{array}{l}\text { dozen expensive chairs, a table, a } \\
\text { television }\end{array}$ & & \\
\hline 32) There was little-to-no chance that I'd be & 22) There's at least a dozen in & & \\
\hline
\end{tabular}




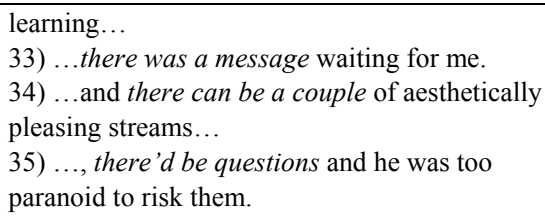

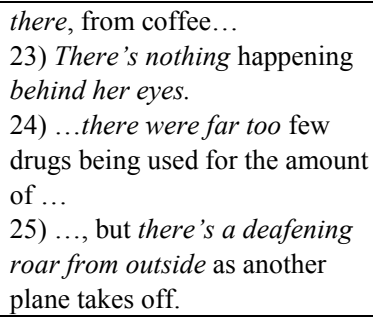

\section{Findings}

Findings reveal that atomic acronym constitutes the highest percentage with $81 \%$ than 'molecular' which constitutes $19 \%$. As for 'phrasal compounds' that involve 'lexical means and lexical relationships', they constitute the highest level which reads $44 \%$. The next highest percentage is found in 'prepositional phrasal compound' that constitutes $25 \%$, 'conjunctional phrasal compounds' reveals $19 \%$, whereas those phrasal compounds which involve 'noun, pronoun and adjective' compose $13 \%$. Phrasal compounds containing a verb is associated with the value zero (Nil) in this data.

The existential sentence type, or 'there-family', in science fiction contemporary short stories takes a number of different syntactic forms. Briefly, 'bare existential' compose the large number with 53\%, second level has gone to 'locative existential' with $38 \%$ percentage. Two lowest percentages have been found in those sentences with a 'definite expression', which have the structure: (There + be + definite expression) and constitute $6 \%$, and existential sentences with a verb other than 'be' read only $3 \%$. This is due to the distinctive differences among types of existential sentences.

It is worth stating that existential sentences of the type 'subject-verb inversion' has a very little consideration in this type of short stories. They read only 2 instances from the whole data:

1) And there he was

2) There he was!

And since it is out of the model analysis (it is mentioned only in one short story: 'Galactic Stress'), the researcher refers to it only in this section.

\section{Conclusion}

The study exposes the productiveness of atomic acronym in science fiction short stories. As for the existential sentences of 'there-family', the paper affirms the absolute existence of a person/thing that have the construction: (there, be, nominal expression) in science fiction stories. Another consideration is also given to locative existential sentences in these stories as they claim the existence of an entity in a certain location.

It is believed that writers of science fiction short stories refer occasionally to existential sentences for linguistic and rhetorical purposes: to assert existence, to present new information and may be to introduce topics. 'Phrasal compounds', on the other hand, may allow easy employment in fiction/science fiction stories because of their pithiness and being graphically notice.

In a nut shell, existential sentences may give the entire clause a fresh status.

\section{References}

Bauer, L. (2001). Compounding. In M. Haspelmath, K. Ekkehard, O. W. R. Wulf (Eds.), Language Typology and Language Universals (pp. 695-707). Berlin: Mouton de Gruyter.

Bauer, L. (1983). English Word-Formation. Cambridge: Cambridge University Press.

Best, S. (2001). The Postmodern Adventure: Science, Technology, and Cultural Studies at the Third Millennium. The Guilford Press Print.

Biber, D., Johansson, S., Leech, G., Conrad, S., \& Finegan, E. (1999). Longman Grammar of Spoken and Written English. London: Pearson Education Education Ltd.

Booij, G. (2007). The grammar of words. Oxford, UK: Oxford University Press. https://doi.org/10.1093/acprof:oso/9780199226245.001.0001

Booker, M., \& Thomas, A. (2009). The science fiction handbook. Malden, MA: Wiley-Blackwell.

Bolinger, D. (1977). Meaning and Form. London: Longman. 
Bostrom, N. (2008). A History of Trans humanist Thought. Journal of Evolution and Technology, 14(1).

Breivik, L. E. (1975). The use and Non-Use of 'Existential there' in Present-Day English. Forum Linguisticum. Contributions to Applied Linguistics 2, 58. "Existential sentences revisited", Papers from the 4th Scandinavian Conference of Linguistics.

Brotherton, M. (ed.) (2009). Diamond in the Sky. Retrieved from http://www.National ScienceFiction.com

Collins, P., \& Carmella, H. (2000). English Grammar: An Introduction. London: Macmillan Publisher.

Danks, D. (2003). Sepmorphemic Blends: A Formal Investigation of the Blending Process in English and its Relationship to Associated Word Formation Processes. University of Liverpool.

Downing, A., \& Philip, L. (1992). English Grammar: An Introduction. London: Prentice Hall International.

Eastwood, J. (1994). Oxford guide to English grammar. Oxford: Oxford University Press.

Francez, I. (2009). Existentials, Predication, and Modification. Linguistics and Philosophy, 32, 1-50. https://doi.org/10.1007/s10988-009-9055-4

Jesperson, O. (1949). A Modern English Grammar on Historical Principles (v111). London: Allen and Unwin.

Kean, D. (2013). Considering: Science Fiction for Idealistic Minds. Retrieved from http://www.obooko.com

Ljung, M. (2003). Making Words in English. Lund: Studentlitteratur.

McNally, L. (2011). Existential sentences. In C. Maienborn, v. H. Klaus \& P. Paul (Eds.), Semantics: An International Handbook of Natural Language Meaning (Vol. 2, pp. 1829-1848). Berlin: Mouton de Gruyter.

Nosek, J. (1985). Quotational Compounds in Modern English and Czech. Philologica Pragensia, 28, 159-164.

Plag, I. (2002). Word Formation in English. Cambridge: CUP.

Quirk, R., Sidney G., Geoffrey, L., \& Jan, S. (1985). Comprehensive Grammar of the English language. London: Longman.

Ralli, A. (2013). Compounding in Modern Greek. London: Springer Science and Business Media. https://doi.org/10.1007/978-94-007-4960-3

Raitt, D., Warmbein, B. (2004). Tales of Innovation and Imagination: Selected Stories from the 2003 Clarke-Bradbury International Science Fiction Competition. The Netherlands: ESA Publication Division.

Reynolds, G. Concept. (2008). Retrieved from http://conceptscifi.com

Reynolds, G. Concept. (2009). Retrieved from http://conceptscifi.com

Rieder, J. (2012). What is SF? Some Thoughts on Genre. A Virtual Introduction to Science Fiction. Ed. Lars, Schmeink. Retrieved from http://virtual -sf.com

Ross, J. (1974). There, there, (there, (there,)). In M. LaGaly, R. Fox \& A. Bruck (Eds.), Papers from the Regional Meeting of the Chicago Linguistic Society (= CLS) 10. Chicago, IL: Chicago Linguistic Society.

Stockwell, P. (2000). The Poetics of Science Fiction. Nottingham: Longman.

Thomas, P. (2013). Science Fiction and Speculative Fiction-Challenging Genre. Boston: Sense Publisher. https://doi.org/10.1007/978-94-6209-380-5

Thomas, P. (2010). Challenging Genres: Comic Books and Graphic Novels. Netherlands: Sense Publishers.

\section{Copyrights}

Copyright for this article is retained by the author, with first publication rights granted to the journal.

This is an open-access article distributed under the terms and conditions of the Creative Commons Attribution license (http://creativecommons.org/licenses/by/4.0/). 